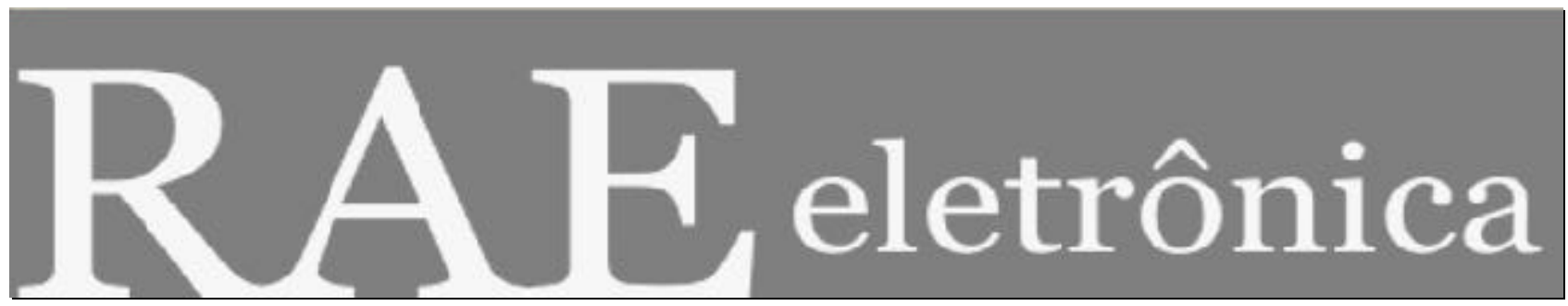

\title{
COMPROMETIMENTO NO TRABALHO E SUA SUSTENTAÇÃO NA CULTURA E NO CONTEXTO ORGANIZACIONAL
}

Por:

Livia de Oliveira Borges

Ana Maria de Souza Lima

Elson Cunha Vilela

Suerda da Silva Guedes Morais

RAE-eletrônica, v. 3, n. 1, Art. 8, jan./jun. 2004

http://www.rae.com.br/eletronica/index.cfm?FuseAction=Artigo \&ID=1878\&Secao=ORGANIZA\&Vol ume $=3 \&$ Numero $=1 \&$ Ano $=2004$

CCopyright, 2004, RAE-eletrônica. Todos os direitos, inclusive de tradução, são reservados. É permitido citar parte de artigos sem autorização prévia desde que seja identificada a fonte. A reprodução total de artigos é proibida. Os artigos só devem ser usados para uso pessoal e nãocomercial. Em caso de dúvidas, consulte a redação: redacao@ rae.com.br.

A RAE-eletrônica é a revista on-line da FGV-EAESP, totalmente aberta e criada com o objetivo de agilizar a veiculação de trabalhos inéditos. Lançada em janeiro de 2002, com perfil acadêmico, é dedicada a professores, pesquisadores e estudantes. Para mais informações consulte o site www.rae.com.br/eletronica.

\section{RAE-eletrônica}

ISSN 1676-5648

(C2004 Editora: Fundação Getulio Vargas - Escola de Administração de Empresas de São Paulo
F U N D A C Ã 0 GETUUO VARGAS

Escole se Adiminisismagäo de Fripresis de Sáo Paulo 


\title{
COMPROMETIMENTO NO TRABALHO E SUA SUSTENTAÇÃO NA CULTURA E NO CONTEXTO ORGANIZACIONAL
}

\section{RESUMO}

O artigo relata uma pesquisa empírica desenvolvida, numa perspectiva psicossocial, numa biblioteca universitária. Objetivou explorar como a variabilidade do comprometimento dos empregados no trabalho estava sustentado em aspectos da estrutura da organização e do comportamento organizacional (motivação, valores organizacionais, satisfação, significado do trabalho). Desenvolveurse a pesquisa durante o primeiro trimestre do ano de 2002, quando aplicaram-se diversas técnicas de coleta de dados (análise documental, observação, entrevista e aplicação de questionários estruturados) e, por consequiência, várias técnicas de análise de dados entre as quais técnicas quantitativas (por exemplo, correlações). Encontraram-se que dificuldades motivacionais, insatisfações salariais e com promoções, cultura organizacional frágil, diversidade de vínculos empregatícios e ausência de um plano de carreira atualizado não permitiam as atitudes comprometidas se concretizarem no comportamento organizacional dos participantes das amostras de estudo. Ações de gestão, como a institucionalização de espaços de participação e investimento na gerência média, podem ajudar a superar os problemas identificados.

\begin{abstract}
An empirical research was developed under the psychosocial approach in a system of university libraries. Its objective was to explore how the variability of work commitment depended on aspects of organizational structure and organizational behavior (motivation, organizational values, satisfaction, work meaning). The data was collected during the first quarter of 2002, using techniques such as document analysis, observation, interview and structured questionnaires, leading to varied strategies of data analysis among which were quantitative techniques as, for example, correlation. The results showed that motivational difficulties, dissatisfactions about wages and promotions, weak organizational culture, diversity of employment contracts, and absence of career plan did not permit that attitudes of commitment were converted into organizational behavior by the participants of the study. Management actions, as the institutionalization of participation and investments on intermediary management may help to overcome the identified problems.
\end{abstract}

\section{PALAVRAS-CHAVE}

Cultura organizacional, entrevistas, análises quantitativas, comprometimento no trabalho, estrutura organizacional.

\section{KEY-WORDS}

Organizational culture, interviews, quantitative analysis, work commitment, organizational structure. 


\section{INTRODUÇÃO}

A literatura especializada (por exemplo, Kiernan, 1998) identifica megatendências de mudanças, como: a revolução digital, removendo fronteiras geopolíticas e organizacionais; a rápida globalização dos mercados, as associações do capital financeiro à inovação gerencial; o advento de uma economia baseada no valor do conhecimento, da informação e da inovação; a gradativa incapacidade dos governos nacionais em controlar seus próprios destinos político-econômicos; o crescimento do "terceiro setor" que torna difícil a distinção entre os setores público e privado; as formas inéditas de organização intra e interempresarial; o acirramento da concorrência; e a crescente preocupação ecológica. Tal variedade de mudanças compelem as organizações ao desenvolvimento de estratégias de adaptação e que lhes confiram vantagem competitiva.

Tais mudanças, a despeito de gerarem resultados socialmente valorizados, como a diversidade de produtos, as novas possibilidades de comercialização e acesso aos mesmos, as novas profissões e ocupações têm gerado também novas dificuldades e desafios, como: aprofundamento das questões éticas relativas aos conhecimentos técnico-científicos; aumento das desigualdades sociais, reorganização dos movimentos sociais frente a esse aumento; mudanças no perfil populacional, precarização das relações de trabalho, insegurança de diversas ordens (do emprego, do mercado de trabalho, da renda, na contratação, nos requisitos exigidos para o emprego) (Tractenberg, 1999; Mattoso, 1995).

Este cenário, embora de forma tardia e heterogênea, como acentua Mattoso (1995), vem se consolidando no Brasil, a partir dos anos 90, tanto no setor privado como no público. Neste último, observa-se o encolhimento do Estado, as tentativas de modernização administrativa, incluindo mudanças de gestão e de tecnologia, e a adoção de políticas poupadoras de mão-de-obra. Estas últimas se manifestam, por exemplo, na redução das contratações, na diversificação de vínculos empregatícios e na estagnação dos salário s.

Neste contexto, mudam os desafios que aqueles que gerenciam pessoas se vêem a frente, entre os quais Garay (1997) destaca: a polivalência; a multifuncionalidade do trabalhador; e o requerimento de mãode-obra com maior capacitação e disposta a participar, aprender e cooperar. Entretanto, tais mudanças vêem acompanhadas da retirada ou redução do sistema de amparo ao trabalhador (estabilidade, planos de carreira, sistema de benefícios e assistência etc.).

Os indivíduos questionam a racionalidade de envolver-se e comprometer-se com as organizações. Essas em busca da eficácia aumentam o apelo ao comprometimento e envolvimento efetivo com as tarefas. No entanto, constata-se um contra-senso nestes apelos quando, ao mesmo tempo, as políticas de pessoal se sustentam na volatilidade do trabalho.

Considerando a heterogeneidade da reestruturação produtiva e de suas conseqüências, não se pode perder de vista que o comprometimento requerido importa, como destaca Garay (Op. cit.), numa intensificação do trabalho, da dependência à organização; e da exposição a situações mais estressogênicas. Fatores esses que implicam sobre a saúde e a qualidade de vida das pessoas.

Estudiosos têm perseguido soluções que preservem a qualidade de vida das pessoas. Maslach e Leiter (1994) e Jaffe (1995), por exemplo, propõem uma definição de efetividade organizacional que envolve o quanto uma organização contribui para a saúde, o bem-estar, o desenvolvimento e o atendimento das 


\section{ORGANIZAÇÕES - COMPROMETIMENTO NO TRABALHO E SUA SUSTENTAÇÃO NA CULTURA \\ E CONTEXTO ORGANIZACIONAL \\ Livia de Oliveira Borges - Ana Maria de Souza Lima - Elson Cunha Vilela - Suerda da Silva Guedes Morais}

necessidades das pessoas: empregados, fornecedores, acionistas, clientes e a comunidade em geral.

Entende-se que a aplicação de estratégias de tal natureza depende de decisões políticas nas organizações, mas também da geração de conhecimentos sistemáticos e atualizados sobre o comportamento organizacional. Assim, investigações que procurem lançar luzes sobre a compreensão do comprometimento com o trabalho e suas relações com aspectos do comportamento organizacional podem contribuir significativamente para que a saúde organizacional e de seus membros possa ser viabilizada.

Com esse propósito, o presente estudo objetiva explorar diversos aspectos da vida organizacional os quais possam afetar o comprometimento no trabalho de funcionários de um sistema de bibliotecas. Na seção subsequiente, à medida que se expõe o referencial teórico, apresenta-se também os objetivos específicos traçados para atingir este objetivo geral.

\section{REFERENCIAL TEÓRICO}

Adotou-se uma perspectiva de análise psicossocial, que integra diversos níveis de explicação intraindividual, interpessoal, posição social dos atores, influências ideológicas - e considera que as ações dos indivíduos são necessariamente sócio-históricas e construídas processualmente pelo conjunto dos indivíduos implicados, conforme as inter-relações estabelecidas entre eles (Álvaro-Estramiana, 1995, Katzell, 1994; Kozlowski e Klein, 2000). Desta forma, assume-se o pressuposto existencialista (Giles, 1989; Sartre, 1961; Aktouf, 1993), retratado nas palavras de Sartre (1961, p. 239), segundo o qual "o Homem primeiramente existe, se descobre, surge no mundo; e que só depois se define", toma consciência de sua existência. Tal pressuposto implica que o plano material da vida é primário em relação aos planos social e psíquico. Mas implica também que é o próprio homem que se concebe a partir da sua existência. É, portanto, construtor de sua própria subjetividade e, por conseqüência, "responsável por aquilo que é" (Sartre, 1961, p. 243). Da mesma forma, o ambiente psicossocial, sendo construção humana, é factível de mudanças projetadas por este homem.

Assumir tal perspectiva de análise tem várias implicações no que se refere aos conceitos e às estratégias metodológicas adotadas. Conduz a conceber-se as organizações como "formações sociais continuamente criadas e recriadas pelos atores organizacionais" (Weick, apud Peiró, 1996). Sendo eminentemente humanas, são sócio-históricas de forma que seus objetivos têm sentido em determinado contexto (Peiró, 1996). São passíveis de mudanças, implementadas deliberadamente ou não, e contam com um dimensão simbólica compartilhada por todos os seus participantes (dirigentes, empregados, usuários e outras instituições parceiras), a qual pode ser designada de cultura organizacional.

Outra implicação da adoção da perspectiva psicossocial refere-se à concepção do comportamento organizacional, articulando atos humanos individuais e condutas coletivas. Assim, cada ato dos indivíduos é também um ato da organização. Em outras palavras, o comportamento organizacional é "visto como uma combinação resultante dos efeitos das diferenças individuais e contextuais" (Kozlowski e Klein, 2000), portanto também articula os diversos níveis de análise seguindo as tendências das revisões sobre comportamento organizacional do Anual Review of Psychology (Rousseau, 1997; Weick e Quinn, 1999; Wilpert, 1995). Estas considerações teóricas fortalecem a necessidade de apreender o contexto organizacional na busca de compreensão de qualquer componente do comportamento organizacional. A implicação metodológica mais imediata desta forma de conceber as organizações e o comportamento organizacional ocorre no estabelecimento do primeiro objetivo específico do estudo:

- Objetivo específico 1. Descrever o contexto sócio-organizacional de um sistema de bibliotecas. 


\section{ORGANIZAÇÕES - COMPROMETIMENTO NO TRABALHO E SUA SUSTENTAÇÃO NA CULTURA \\ E CONTEXTO ORGANIZACIONAL \\ Livia de Oliveira Borges - Ana Maria de Souza Lima - Elson Cunha Vilela - Suerda da Silva Guedes Morais}

A perseguição deste objetivo guiourse pela identificação e conceituação das dimensões das organizações de Srour (1998), a saber: (1) Dimensão Econômica, referente à organização enquanto produtora de bens ou serviços econômicos; (2) Dimensão Política, referente às definições da organização como produtora de bens ou serviços políticos decorrentes dos interesses sociais e das decisões imperativas da organização frente às relações de poder; (3) Dimensão Simbólica que define a organização como produtora de bens e serviços simbólicos os quais dependem principalmente dos padrões culturais.

Quando se fala em articulação dos níveis de análise individual e coletivo, pressupõe-se que os fenômenos psicossociais são inter-relacionados à despeito da fragmentação temática do campo da Psicologia Organizacional e do Trabalho (Spink, 2001; Bastos, 1996; Borges, 1998; 2001; Siqueira, 2002). Esta fragmentação segue a um extremo tal, que os diversos temas estudados se sobrepõem e, muitas vezes, tornam-se de difícil distinção. Por isso, tem se observado uma tendência (Borges, 2001; Siqueira, 2002; Katzell, 1994) a estudar diversos construtos nas suas inter-relações, permanecendo numa perspectiva de construção probabilística da realidade (Álvaro-Estramiana, 1995).

Seguindo tal perspectiva, assinala-se que para explorar a dimensão simbólica do contexto organizacional é preciso recorrer ao conceito de cultura. Esse é um construto complexo como assinala Aktouf (1994, p. 47): "algo muito vasto,... inscrita muito profundamente nas estruturas sociais, na história, no inconsciente, na experiência vivida e no vir a ser coletivo humano...”. Em consequiência, observa-se uma tendência dos autores em identificar uma variedade de componentes da cultura, como suposições implícitas, valores, normas, significados, mitos, filosofias de vida, heróis e estórias ${ }^{i}$. A opção aqui foi estudar a cultura organizacional a partir de construtos específicos dos quais destacamos os valores organizacionais.

Os valores são considerados um dos principais componentes da cultura organizacional, por vários estudiosos do tema (por exemplo: Aktouf, 1994; Hofstede, 1984; Schein, 1990; Triandis, 1994a e b). Para nortear a identificação dos valores organizacionais, fundamenta-se na aplicação (Tamayo, 1996) do modelo dos valores culturais (Ros e Schwartz, 1995; Schwartz, 1999; Schwartz e Ros, 1995). Os valores são usados para caracterizar culturas, o que implica em serem compartilhados socialmente e serem idéias abstratas sobre o que é certo, bom e desejável para uma sociedade. Valores organizacionais são, por sua vez, aqueles que os indivíduos atribuem às organizações. Guiam e justificam decisões e adoção de políticas nas organizações.

O acúmulo de pesquisas sobre os valores culturais mostram que se estruturam em três dimensões bipolares, a saber: (1) Conservadorismo (manutenção do status quo, propriedade e manutenção da solidariedade grupal) versus Autonomia (promoção ou proteção dos direitos e ideais independentes, na curiosidade e na criatividade); (2) Hierarquia (legitimação da alocação hierárquica dos papéis e recursos sociais) versus Igualitarismo (transcendência dos interesses em favor do bem-estar de todos); (3) Harmonia (relação harmoniosa com o ambiente) versus Domínio (assertividade e competência na transformação do meio social ou natural). As duas primeiras dimensões referem-se aos valores que guiam a vida interna de uma organização e a última, às relações externas.

Na intenção de realizar o propósito geral desse estudo, seguiu-se estabelecendo um objetivo que se reporta ao relacionamento dos indivíduos (trabalhadores) com a organização e/ou com o trabalho:

- Objetivo específico 2. Explorar o relacionamento dos funcionários do sistema de bibliotecas com a organização e com o trabalho através de suas reações de satisfação e motivacionais bem como de atribuição de significados.

Esse objetivo envolve três construtos psicossociais: significado, satisfação e motivação no trabalho. A exploração de todos três contribuirá no aprofundamento da compreensão da dimensão simbólica da 


\section{ORGANIZAÇÕES - COMPROMETIMENTO NO TRABALHO E SUA SUSTENTAÇÃO NA CULTURA \\ E CONTEXTO ORGANIZACIONAL \\ Livia de Oliveira Borges - Ana Maria de Souza Lima - Elson Cunha Vilela - Suerda da Silva Guedes Morais}

organização. O primeiro deles - significado do trabalho - apresenta complementariedade aos valores organizacionais. Enquanto, esses enfocam a organização e o que o indivíduo espera dela, o significado do trabalho focaliza os sentidos que o trabalho tem para os indivíduos. Continua sendo um componente da cultura porque, embora seja uma cognição subjetiva, derivando do processo de atribuir significados de forma que varia individualmente, é também social porque apresenta aspectos compartilhados, associados às condições históricas da sociedade (Borges, 1998; Borges e Tamayo, 2001).

É também um fenômeno complexo, sendo consensualmente entendido como multifacetado, (por exemplo, MOW, 1987; Soares, 1992; Brief e Nord, 1990; Borges-Andrade, Martins e Abbad, 1995). Não há, entretanto, consenso no conjunto de facetas a serem consideradas. Optourse por um modelo testado em estudos nacionais, que tem revelado consistência e adequação (Borges, 1997; 1998; Borges e Tamayo, 2001). Tal modelo identifica como facetas do significado do trabalho: a centralidade do trabalho, os atributos valorativos e descritivos e a hierarquia dos mesmos. A centralidade do trabalho refere-se à importância que o indivíduo atribui ao trabalho, comparando-o às outras esferas de vida: família, lazer, religião e comunidade (England e Misumi, 1986; MOW, 1987).

Atributos valorativos referem-se às características atribuídas ao trabalho, as quais oferecem uma definição de como esse deve ser. São, portanto, os valores do trabalho. Os atributos descritivos designam o que o trabalho $\underline{\underline{e}}$ concretamente (Borges, 1998; Borges e Tamayo, 2001).

Hierarquias de atributos referem-se aos arranjos individuais que consistem na organização dos diversos atributos valorativos e descritivos segundo a ordem de importância dos mesmos. Estudiosos sobre valores humanos (por exemplo, Rokeach \& Ball-Rokeach, 1989; Schwartz \& Ros, 1995; Tamayo, 1994) têm ressaltado que as pessoas e as culturas se diferenciam mais pela ordem de prioridade atribuída aos valores do que pelos mesmos.

O segundo construto mencionado - satisfação no trabalho - refere-se a uma resposta afetiva e emocional que o indivíduo estabelece com o seu trabalho e pressupõe a avaliação cognitiva e subjetiva que realiza sobre o mesmo (Muchinsky, 1994). Para explorar os níveis motivacionais, adota-se a conceituação de Vroom (1995), segundo o qual a Força Motivacional é o produto de três componentes: valência (atratividade ou repulsão de um determinado resultado do trabalho), expectativa (probabilidade subjetiva de um determinado resultado ocorrer) e instrumentalidade do desempenho (utilidade do desempenho profissional para a consecução de um determinado resultado do trabalho).

O terceiro objetivo específico volta-se para aquele construto foco das queixas da direção da organização - o comprometimento organizacional - sendo:

- Objetivo específico 3. Identificar a variabilidade do comprometimento no trabalho dos funcionários da organização.

Adotou-se o conceito de Bastos (1994, p.86), segundo o qual se comprometer implica sentimento de "lealdade em relação a algo" e o comprometimento organizacional está relacionado a uma resposta dada em função do tratamento oferecido pela organização, tratamento este que possibilite oportunidade de desenvolvimento pessoal e profissional. $\mathrm{O}$ mesmo autor expõe, também, que o comprometimento no trabalho não é uno, mas diverso em conformidade com o seu objeto, chamando atenção para três focos de manifestação: a profissão, o sindicato e a organização.

Outros estudos sinalizam para a multidimensionalidade do comprometimento organizacional. Meyer e Allen (apud Medeiros, 1997), por exemplo, desenvolveram investigação na qual as principais dimensões do 


\section{ORGANIZAÇÕES - COMPROMETIMENTO NO TRABALHO E SUA SUSTENTAÇÃO NA CULTURA \\ E CONTEXTO ORGANIZACIONAL \\ Livia de Oliveira Borges - Ana Maria de Souza Lima - Elson Cunha Vilela - Suerda da Silva Guedes Morais}

comprometimento - atitudinal, instrumental e normativa - estão incorporadas. Tal trabalho ofereceu suporte para pesquisa realizada com pequenas empresas no Brasil (Medeiros, 1997). Optou-se, no entanto, pela atenção aos focos de comprometimento estudados por Bastos por considerá-los mais adequados para a exploração de relações com outros construtos (significado do trabalho, motivação, satisfação).

O último objetivo específico retoma as associações entre comprometimento organizacional e os demais construtos (valores, significado do trabalho, motivação e satisfação no trabalho), sendo:

- Objetivo específico 4. Explorar associações entre a variabilidade do comprometimento no trabalho e os demais aspectos investigados do comportamento organizacional e refletir sobre estas associações a luz do contexto organizacional.

O planejamento do presente estudo abrangeu uma diversidade de temas de comportamento organizacional, por isso não se aprofundou em cada construto, mas apenas nos aspectos indispensáveis para compreender a associação entre os mesmos, o que é foco do estudo. Recomenda-se que, se tal aprofundamento é a necessidade do leitor, deve recorrer à bibliografia citada e outras disponíveis.

\section{MÉTODO}

O presente estudo realizou-se no primeiro trimestre de 2002, contando com uma equipe formada por 46 pessoas, das quais 42 eram alunos de graduação, que executaram atividades de coleta de dados, participaram e acompanharam as demais etapas do estudo, e quatro, os autores deste artigo, que coordenaram o projeto.

Foi desenvolvido em um sistema de biblioteca universitário e faz parte de um estudo mais amplo. Por isso, nesta seção descreve-se apenas as técnicas necessárias à consecução dos objetivos apresentados anteriormente. Assim, visando a consecução do primeiro objetivo específico, que demanda caracterizar o contexto interno e externo de uma biblioteca universitária, foram realizadas as seguintes atividades: (a) entrevista semi-estruturada da dirigente principal, cujo roteiro foi construído de acordo com as dimensões da organização identificadas por Srour (1998); (b) observação de campo, em subgrupos, sem aviso prévio das datas aos dirigentes, para conhecer o ambiente físico; (c) levantamento de informações documentais (estatuto, regimentos, planos, etc.); e (d) aplicação de questionário estruturado (1 página) a usuários da biblioteca, na saída da sua sede, indagando sobre o motivo da visita, a consecução do objetivo, a qualidade do atendimento, a frequiência das visitas e a utilização dos serviços.

Para a consecução dos demais objetivos e para aprofundamento da exploração sobre a dimensão simbólica da organização foram aplicados dois conjuntos de questionários em duas amostras de funcionários da organização, evitando o preenchimento de um número excessivo de questionário pelos participantes. Foram incluídos funcionários com os três vínculos contratuais existentes na organização - servidores do quadro efetivo, bolsistas e pessoal terceirizado - porque todos contribuem na construção do comprometimento no trabalho, da cultura da organização e demais reações (satisfação e motivação ao trabalho).

O sistema de biblioteca tem um quadro de 50 funcionários, dentre os quais 10 são servidores técnicosadministrativos (quadro efetivo), 32 bolsistas e 8 funcionários terceirizados. As duas amostras apresentaram as características sócio-demográficas resumidas na Tabela 1, revelando que são bastante semelhantes. 
Tabela 1: Características sociodemográficas dos participantes da amostra

\begin{tabular}{l|c|c}
\hline Características sociodemográficas & Primeira amostra $\mathbf{N = 1 9 )}$ & $\begin{array}{l}\text { Segunda amostra } \\
(\mathbf{N = 1 8})\end{array}$ \\
\hline Sexo & 12 & 13 \\
Masculino & 7 & 5 \\
Feminino & & \\
Idade & 37,6 & 30,4 \\
Média & 12,1 & 12,7 \\
Desvio-padrão & 18,0 & 18,0 \\
Mínimo & 59,0 & 58,0 \\
Máximo & & \\
Tempo de trabalho & 14,2 & 8,9 \\
Média & $<1,0$ & 1,0 \\
Mínimo & 27,6 & 24,0 \\
Máximo & & 1 \\
Instrução & 4 & 17 \\
Menos que o ensino secundário & 15 & 14 \\
A partir do ensino secundário & 14 & 4 \\
Renda & 3 & -- \\
1 a 5 salários-mínimo & 1 & -- \\
6 a 10 salários-mínimos & 1 & 10 \\
11 a 20 salários-mínimos & & 7 \\
Resposta em branco & 11 & -- \\
Estado civil & 7 & \\
Solteiro & 1 & \\
Casado & & \\
Separado ou divorciado & & \\
Não informado & & \\
\hline
\end{tabular}

Para aplicação, os participantes eram procurados nos locais de trabalho, aos quais era solicitado o preenchimento anônimo e opcional dos questionários. Por conseqüência, desta tática de formação das amostras, as mesmas são acidentais.

À primeira amostra, foi aplicado um conjunto de questionários, composto de: Inventário de Motivação e Significado do Trabalho (IMST); Centralidade do Trabalho; Focos de Comprometimento no Trabalho e Ficha Sócio-demográfica. O IMST (Borges e Alves-Filho, 2001) é formado por quatro escalas que medem respectivamente: os atributos valorativos, descritivos, expectativas e instrumentalidade. As duas primeiras escalas se referem a facetas do significado do trabalho e as duas últimas a componentes da motivação. A todas as escalas os participantes respondem atribuindo pontos de 0 a 4 , sendo que: na primeira, o participante examina seus 62 itens, refletindo quanto a frase (item) corresponde a algo que o trabalho deve ser; na segunda, a mesma quantidade de itens, mas refletindo quanto espera ocorrer o resultado do trabalho indicado nos itens; na terceira (também 62 itens), quanto os resultados ocorrem realmente e, na última escala, responde a 49 itens avaliando quanto seu desempenho ou esforço no trabalho contribui para obter o resultado indicado no item. A primeira escala (atributos valorativos) mensura cinco fatores, a saber: (1) Justiça no Trabalho, (2) Desgaste e Desumanização, (3) Realização, (4) Bem-Estar Socioeconômico e (5) AutoExpressão. A segunda escala mensura também cinco fatores: (1) Auto-Expressão, (2) Responsabilidade e Dignidade, (3) Desgaste e Desumanização, (4) Recompensa Econômica e (5) Condições de Trabalho. A terceira escala (expectativas) mensura quatro fatores: (1) Justiça no Trabalho e Auto-Expressão, (2) Desgaste e Desumanização, (3) Bem-estar e Independência e (4) Responsabilidade. A quarta escala (instrumentalidade) mensura, por sua vez, quatro fatores: (1) Envolvimento, (2) Justiça no Trabalho, (3) 


\section{ORGANIZAÇÕES - COMPROMETIMENTO NO TRABALHO E SUA SUSTENTAÇÃO NA CULTURA E CONTEXTO ORGANIZACIONAL \\ Livia de Oliveira Borges - Ana Maria de Souza Lima - Elson Cunha Vilela - Suerda da Silva Guedes Morais}

Desgaste e Desumanização e (4) Independência e Bem-Estar. Os escores nos fatores de cada participante são estimados pela média ponderada dos itens componentes de cada fator, usando como ponderadores as cargas fatoriais de cada item (Borges e Alves, 2001).

Para estimar a força motivacional, primeiramente, dicotomizam-se os escores de atributos valorativos de forma que passam a valer -1 ou +1 . Em seguida, obtém-se o produto dos escores nos fatores de valências, expectativas e instrumentalidade.

O segundo questionário refere-se à Centralidade do Trabalho (England e Misumi, 1986; MOW, 1987; Soares, 1992) e consiste em apenas duas questões. Na primeira, o participante atribui pontos a cinco esferas de vida (família, trabalho, lazer, religião e comunidade) de forma que a soma dos pontos seja igual a 100. Na segunda questão, o participante estima a importância do trabalho, atribuindo-lhe pontos de 1 a 7.

O terceiro questionário do conjunto versa sobre comprometimento no trabalho (Bastos, 1994). Está composto de 24 itens para os quais os participantes respondem utilizando uma escala de 1 (Discordo totalmente) a 7 (Concordo totalmente). Este questionário permite mensurar três fatores que correspondem aos focos de comprometimento de trabalho mencionados anteriormente (profissão, organização e sindicato). Os escores dos participantes nos focos foram estimados pela média aritmética dos pontos atribuídos aos itens que compõem a escala de cada foco.

À segunda amostra foram aplicados o Inventário de Valores Organizacionais (IVO), a Escala de Satisfação no Trabalho (EST) e uma ficha sócio-demográfica. O primeiro (Robayo-Tamayo, 1997; Tamayo, Mendes e Paz, 2001) é composto de 132 itens. Cada item designa um valor específico. Na metade dos itens, o participante avalia a importância que tem para organização (plano real). Na outra metade dos itens, o participante avalia quanto é desejável que aquele valor oriente a vida da organização (plano ideal). A todos os itens os participantes respondem atribuindo ponto de 0 a 6 . Ao final de cada metade do conjunto de itens, o participante escolhe itens dentre os que atribuiu pontos baixos que considera opostos aos seus princípios e, entre os que atribuiu escore máximo, aqueles que são supremos. A estes, no registro de dados, atribuiu-se -1 , quando opostos e 7, quando supremo. As respostas deste questionário depois de computadas geram escores (médias dos itens) para cada um dos pólos axiológicos do modelo de valores culturais descritos anteriormente (conservação versus autonomia, hierarquia versus igualitarismo, domínio versus harmonia).

O questionário de satisfação no trabalho (Siqueira, 1995) aplicado é composto de 25 itens, aos quais os participantes respondem atribuindo pontos de 1 a 7 que variam de totalmente insatisfeito a totalmente satisfeito. Depois de registradas e computadas as respostas, obtém-se escores dos indivíduos em 5 fatores, a saber: satisfação com os colegas de trabalho, com o salário, com a chefia, com a natureza do trabalho e com promoções.

Todos os questionários utilizados apresentam parâmetros psicométricos que comprovam consistência e validade, podendo o leitor, que necessita os conhecer, consultar a bibliografia citada.

As respostas dos participantes aos questionários foram registradas na forma de banco de dados do SPSS for Windows (Statistical Package for Social Science), visando facilitar o desenvolvimento das análises estatísticas (estatísticas descritivas, correlações e teste t). 


\section{RESULTADOS}

\section{O contexto organizacional}

O sistema de biblioteca tem o papel de promover o uso e a disseminação da informação científica e tecnológica, servindo de suporte para o ensino, a pesquisa e a extensão. Oferece vários serviços, como: consulta local, empréstimo domiciliar e entre biblioecas; comutação, orientação e pesquisa bibliográfica; normalização de documentos; catalogação na fonte; ISBN; ISSN (códigos internacionais de identificação de livros e periódicos); direitos autorais; visitas programadas e acesso à INTERNET.

Sua clientela principal é formada por professores, alunos e funcionários que têm acesso pleno aos serviços, porém qualquer cidadão pode consultar seu acervo. Registra-se uma média de frequiência diária de 3.500 usuários. Apesar da existência de um trabalho de divulgação dos serviços do sistema de biblioteca, a maioria dos usuários os desconhece e tende a usar prioritariamente os mais tradicionais. Este fato, provavelmente, está associado aos hábitos cristalizados dos usuários, que ainda não incorporaram o hábito de utilizar os serviços mais recentes. Essa hipótese sustenta-se na observação, que na hora de atribuir importância aos serviços, os usuários incluem o acesso a INTERNET entre os principais serviços, porém utilizam mais a biblioteca como um local de estudo. Não se elimina a possibilidade de que a mudança de hábitos também encontre dificuldades em se estabelecer por razões, como o descrédito sobre a atualização do acervo e/ou o fato de serviços como levantamentos bibliográficos na INTERNET serem acessíveis em outros lugares, na universidade. Os usuários percebem o acervo como insuficiente e demandam melhorias de atendimento.

O acervo é composto por 270.000 volumes. Mantém-se uma meta de aquisição de 600 novos livros a cada mês. A aquisição dos livros é planejada a partir das solicitações dos departamentos acadêmicos.

O sistema de biblioteca é um órgão suplementar de uma Universidade, diretamente subordinada ao reitor. Submete-se ao estatuto e regime geral da referida instituição, além de ter seu próprio regimento, o qual estabelece uma estrutura organizacional de linha/staff e a competência de cada um de seus órgãos. Essa estrutura tradicional contrasta com as tentativas da Direção em criar espaços de participação coletiva na administração do sistema, retirando o respaldo que tais iniciativas deviam contar.

Constitui-se de sua sede central, de bibliotecas setoriais - destinadas ao atendimento aos usuários em unidades afastadas do Campus Universitário central - e de bibliotecas especializadas - voltadas para as demandas específicas da pós-graduação.

A sede da biblioteca (que centraliza a maior parte do acervo) dispõe de adequada estrutura física e dos equipamentos necessários ao seu funcionamento. O quadro de pessoal do sistema é, porém, insuficiente, o que vem sendo suprido por pessoas com vínculos temporários de emprego (bolsistas e terceirizados). Essa solução torna a gestão de pessoas mais complexa demandando novos critérios de eqüidade. Os funcionários efetivos, sob o reconhecimento da direção e a exemplo dos demais funcionários técnicos administrativos da universidade, reclamam a falta de um plano de carreira atualizado. As decisões sobre contratação e sobre estabelecimento de carreira funcional extrapolam as possibilidades de decisão da direção do sistema de biblioteca.

O nível de qualificação do quadro efetivo e a política de treinamento constituem se em pontos fortes da gestão de pessoal. O pequeno número de funcionários efetivos, porém, encontra-se concentrado em 


\section{ORGANIZAÇÕES - COMPROMETIMENTO NO TRABALHO E SUA SUSTENTAÇÃO NA CULTURA E CONTEXTO ORGANIZACIONAL \\ Livia de Oliveira Borges - Ana Maria de Souza Lima - Elson Cunha Vilela - Suerda da Silva Guedes Morais}

uma única atividade o que, provavelmente, transmite uma desvalorização da atividade de atendimento e, simultaneamente, de quem a realiza.

A fala da diretora na entrevista e demais contatos revela um envolvimento acentuado com a realização plena da missão do sistema de bibliotecas, apresentando um claro entusiasmo com os avanços em crescimento e modernização do mesmo. Tal envolvimento também se reflete no entusiasmo com o andamento do estudo objeto do presente artigo.

A Direção queixa-se de diferenças de comprometimento entre os participantes do quadro de pessoal. Tais desigualdades podem, por sua vez, estarem associadas a problemas como a variedade de vínculo empregatício, a falta de perspectivas de crescimento funcional.

A dimensão simbólica da organização foi também explorada a partir da percepção dos funcionários dos valores organizacionais. Os resultados encontrados revelam uma hierarquização dos pólos axiológicos no plano ideal em dois patamares de importância a saber: (1) autonomia e conservação e (2) hierarquia, harmonia, domínio e estrutura igualitária. No plano real, os patamares de importância são: (1) autonomia e conservação; (2) igualitarismo; (3) harmonia, hierarquia e domínio.

As diferenças médias entre os escores, nos dois planos de análise (ideal e real), dos mesmos pólos tendem a ser pequenas, sendo a diferença referente ao Igualitarismo mais ampla que as demais. Todas as diferenças médias entre os dois planos de análise são negativas, implicando na tendência a atribuir escores mais elevados à realidade concreta que ao ideal.

Estes resultados, por um lado, são positivos porque indicam a existência de conflitos leves de valores. Como Tamayo (1999) mostra que os conflitos de valores organizacionais oferecem forte previsibilidade ao clima organizacional, os conflitos leves encontrados podem se constituir em um indicador positivo do clima psicossocial do sistema de biblioteca em análise. Por outro lado, as hierarquias com poucos patamares, principalmente no plano ideal, indicam também baixa clareza dos valores organizacionais.

Os escores negativos das diferenças entre os planos de análise, principalmente considerando que as maiores se referem ao igualitarismo, indicam, por sua vez, um desejo de contar com mais controle e ou supervisão por parte dos dirigentes.

\section{Significado do Trabalho}

Quanto à centralidade do trabalho, os participantes da $1^{\mathrm{a}}$ amostra tomam este como a segunda esfera de vida, seguindo à família. Esse resultado segue a tendência observada em outros estudos no país, indicando, simultaneamente, a relativa estabilidade cultural e a influência da macro conjuntura na determinação deste aspecto.

Os resultados encontrados na amostra do presente diagnóstico mostram que uma parcela mais ampla dos respondentes $(36,8 \%)$ toma o fator Auto-expressão como o principal atributo valorativo, outra parcela também ampla $(31,6 \%)$, o fator realização. O fator Bem-Estar-Econômico é tomado como o principal atributo valorativo por $21,1 \%$ da amostra. $10,0 \%$, valoriza igualmente mais de um fator.

Quando se observa a hierarquia dos atributos descritivos, constata-se que 57,9\% percebe como principal característica concreta do trabalho o fator responsabilidade e dignidade e $15,8 \%$, o fator Desgaste e Desumanização. Chama a atenção aqui a dispersão menor das respostas quando comparada 


\section{ORGANIZAÇÕES - COMPROMETIMENTO NO TRABALHO E SUA SUSTENTAÇÃO NA CULTURA \\ E CONTEXTO ORGANIZACIONAL \\ Livia de Oliveira Borges - Ana Maria de Souza Lima - Elson Cunha Vilela - Suerda da Silva Guedes Morais}

com a hierarquia dos atributos valorativos encontradas, indicando haver mais consenso em torno da percepção dos atributos descritivos do que dos valorativos. Este resultado não é usual, posto que em outros estudos citados em que se utiliza este mesmo modelo de compreensão do significado trabalho, a tendência é exatamente a inversa. Esta observação corrobora a reduzida clareza da hierarquização dos valores organizacionais indicados pelos escores nos pólos axiológicos referidos anteriormente.

Exploraram-se as relações dos escores nos fatores com características biográficas (ou sóciodemográficas) dos participantes da amostra, constatando-se correlações estatisticamente significativas entre a idade e três fatores dos atributos valorativos: Justiça no Trabalho $(r=0,48$ para $p=0,04)$, Desgaste e Desumanização $(r=0,46$ para $p=0,05)$ e Realização $(r=0,54$ para $p=0,02)$. Tais correlações são diretamente proporcionais indicando que quanto maior a idade dos participantes, maiores os escores obtidos nos fatores.

Entre os fatores dos atributos descritivos, encontraram-se correlações estatisticamente significativas entre os escores obtidos no fator Recompensa Econômica e idade ( $r=0,75$ para $p<0,001$ ), tempo de trabalho $(r=0,71$ para $p=0,002)$ e tempo de profissão $(r=0,68$ para $p=0,04)$; e entre os escores no fator Condições de Trabalho e Renda individual $(r=0,60$ para $p=0,01)$. Todas as correlações são positivas indicando que os escores nos fatores crescem junto com as referidas características biográficas.

A centralidade do trabalho também está correlacionada positivamente com idade e tempo de trabalho dos participantes $(r=0,56$ para $p=0,02$ e $r=0,68$ para $p=0,005)$.

Tais resultados apontam incongruências entre as definições entre o que o trabalho deve ser e o que seja o trabalho. Sintetizando, pode-se dizer que há uma tendência geral a atribuir bastante importância ao trabalho associado a um desejo de auto-expressão e realização, porém com uma vivência do trabalho concreto como responsabilidade e garantia da dignidade pessoal.

\section{Motivação e Satisfação no Trabalho}

Quanto à satisfação no trabalho, os resultados obtidos indicam que os participantes tendem a apresentar escores que ficam entre Indiferente e Satisfeito nos fatores de satisfação com os colegas, chefia e natureza do trabalho; escores entre insatisfeito e indiferente no fator promoções; e entre muito insatisfeito e insatisfeito, com o salário. A satisfação salarial e com as promoções estão correlacionados com idade e tempo de serviço de forma diretamente proporcional, significando que os mais antigos tendem a estar mais satisfeitos. Estes resultados referentes à satisfação no trabalho estão abaixo do desejável.

Quanto à força motivacional, os escores obtidos pelos participantes variaram entre os escores de 37 a 120, com média de 82,7. O escore de 86 divide a amostra ao meio (mediana). A distribuição de escores aproxima-se bastante de uma curva normal. Tal resultado revela haver bastante variação na força motivacional dos participantes da amostra. Apesar de estatisticamente previsível, tais resultados estão longe do que a organização deve esperar.

Os escores mais baixos em força motivacional derivam da atribuição de baixa instrumentalidade ao desempenho para a obtenção dos resultados desejados, principalmente no que diz respeito à Justiça no trabalho. Ressalta-se, então, que os escores obtidos em instrumentalidade para a Justiça no trabalho, Desgaste e Desumanização e Bem-Estar-Sócio-Econômico estão positivamente correlacionados com idade dos participantes (Respectivamente: $r=0,55$ para $p=0,01 ; r=0,66$ para $p=0,002$ e $r=0,66$ para $p=$ 


\section{ORGANIZAÇÕES - COMPROMETIMENTO NO TRABALHO E SUA SUSTENTAÇÃO NA CULTURA \\ E CONTEXTO ORGANIZACIONAL \\ Livia de Oliveira Borges - Ana Maria de Souza Lima - Elson Cunha Vilela - Suerda da Silva Guedes Morais}

0,002). Estas correlações como as de satisfação com o salário e promoções com idade e tempo de serviço são contrastantes com a realidade de que no sistema de bibliotecas em estudo predomina atualmente contratos temporários.

\section{Comprometimento no trabalho}

Os resultados encontrados indicam comprometimento organizacional e profissional moderadamente positivo (entre 4 e 5) e com sindical, moderadamente negativo (entre 3 e 4). Estes resultados podem ser entendidos como divergentes em relação a queixa da dirigente principal sobre a diversidade de níveis de comprometimento do quadro de pessoal. No entanto, é preciso assinalar que o questionário mensura manifestações atitudinais. A literatura especializada mostra que nem sempre as atitudes têm uma implicação direta na geração da manifestação comportamental correspondente. Atitudes são relacionadas entre si e, por isso, entre a atitude comprometida e o comportamento comprometido podem existir outras variáveis mediando a relação, tanto no sentido de atenuar ou de incrementá-la. Sublinha-se que estes mesmos funcionários que apresentam atitudes comprometidas acima do esperado, apresentam insatisfação principalmente no que se refere a salário e promoções. Por isso, recorda-se que estudos anteriores (por exemplo, Borges-Andrade, Cameschi e Xavier, 1990) mostram que a carreira é um forte preditor de comprometimento.

A exploração do relacionamento dos escores dos participantes da amostra nos focos de comprometimento no trabalho e suas características bio gráficas revelou correlação diretamente proporcional entre renda individual e comprometimento organizacional e profissional (Respectivamente, $\mathrm{r}=0,59$ para $\mathrm{p}=0,01$ e $\mathrm{r}=0,56$ para $\mathrm{p}=0,02$ ) e correlação, também diretamente proporcional, entre renda familiar e comprometimento profissional $(r=0,50$ para $p=0,04)$. Estas correlações encontradas corroboram a hipótese levantada no parágrafo anterior.

\section{As relações entre os escores das diversas medidas em comportamento organizacional}

O desenvolvimento da pesquisa com duas amostras dos funcionários do referido sistema de bibliotecas, para as quais se aplicaram conjuntos distintos de questionário, não possibilita o desenvolvimento de análises estatísticas para a exploração das relações existentes entre todas as medidas utilizadas de comportamento organizacional, mas apenas entre aquelas referentes aos questionários de um mesmo conjunto.

Para tanto, estimaram-se as correlações entre os componentes dos construtos mensurados. A Figura 1 sintetiza graficamente as correlações encontradas que são estatisticamente significativa com a finalidade de tornar mais claro as relações existentes. Entre os escores nos focos de comprometimento (organizacional, profissional e sindical) e nos componentes do significado do trabalho, encontraram-se correlações estatisticamente significativas entre Comprometimento Profissional e o fator valorativo de Bem-Estar Econômico ( $\mathrm{r}=0,53$ para $\mathrm{p}=0,02)$ e entre Comprometimento Organizacional e o fator descritivo de Recompensas Econômicas $(r=0,58$ para $p=0,02)$. Isto significa que os participantes que valorizam mais o Bem-Estar Econômico tendem a estar mais comprometidos profissionalmente e aqueles que percebem mais recompensas econômicas na organização tendem a estar mais comprometidos com mesma.

Da mesma forma, estimaram-se as correlações existentes entre os escores em Comprometimento com os escores dos indicadores motivacionais. Encontraram-se, então, correlações positivas e estatisticamente significativas entre Comprometimento Profissional e Instrumentalidade do desempenho para obter Justiça no Trabalho $(\mathrm{r}=0,48$ para $\mathrm{p}=0,04)$ e entre Comprometimento 


\section{ORGANIZAÇÕES - COMPROMETIMENTO NO TRABALHO E SUA SUSTENTAÇÃO NA CULTURA \\ E CONTEXTO ORGANIZACIONAL \\ Livia de Oliveira Borges - Ana Maria de Souza Lima - Elson Cunha Vilela - Suerda da Silva Guedes Morais}

Organizacional e o mesmo componente motivacional $(r=0,50$ para $\mathrm{p}=0,04)$. Lembra-se aqui que Justiça no Trabalho supõe proporcionalidade entre esforço e as recompensas.

Como os níveis da satisfação com salário e promoções são os mais baixos escores encontrados pela escala de satisfação utilizada no segundo conjunto de questionários, estas associações encontradas entre comprometimento no trabalho e os componentes de significado do trabalho e de motivação, entende-se que permitem sustentar o argumento de que são as insatisfações dos funcionários que minimizam as possibilidades de que as atitudes comprometidas se concretizem no plano comportamental concreto, dando sentido as queixas da direção do sistema de bibliotecas. 


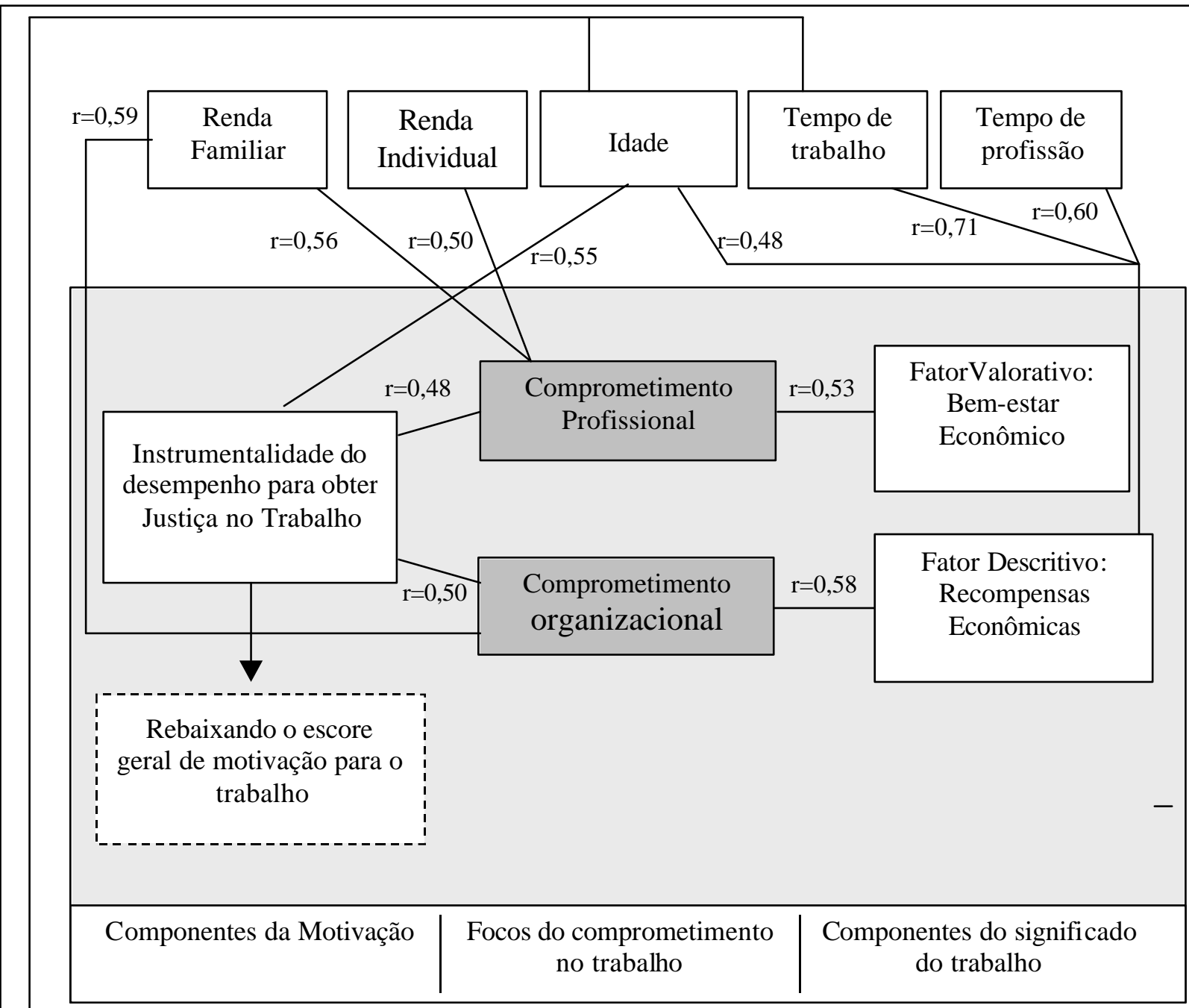

Satisfação com o salário e com promoções

Hipótese: Se predominam escores baixos em satisfação com o salário e com as promoções, então provavelmente tal insatisfação minimiza as possibilidades de que as atitudes comprometidas se concretizem no plano comportamental concreto

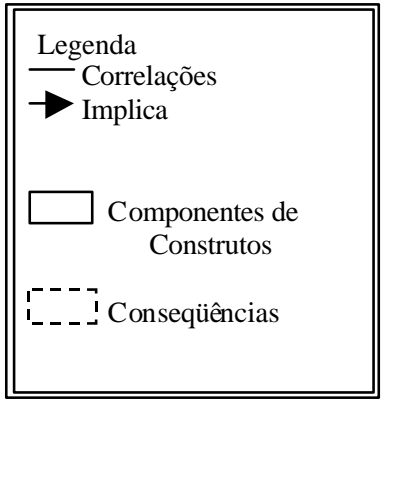

Figura 1: Representação das correlações entre os componentes dos diversos construtos psicossociais e as características sócio-demográficas 


\section{ORGANIZAÇÕES - COMPROMETIMENTO NO TRABALHO E SUA SUSTENTAÇÃO NA CULTURA \\ E CONTEXTO ORGANIZACIONAL \\ Livia de Oliveira Borges - Ana Maria de Souza Lima - Elson Cunha Vilela - Suerda da Silva Guedes Morais}

Essa hipótese é por sua vez fortalecida, observando-se (Figura 1) que o fator descritivo de recompensas econômicas (significado do trabalho) e o fator de instrumentalidade do desempenho para obter justiça (motivação) estão correlacionados com idade dos participantes. O mesmo fenômeno se repete com a satisfação com o salário e com as promoções, embora em amostra distinta da mesma população.

Explorando, por vez, as correlações entre os escores nos fatores de satisfação no trabalho com os escores de descompensações axiológicas (diferenças entre os planos idéias e reais em cada pólo axiológicos) encontramos correlações significativas e inversamente proporcionais entre os escores no fator de satisfação com os colegas de trabalho e os escores em descompensações axiológicas de hierarquia $(r=-0,51$ para $\mathrm{p}=0,03)$ e entre o mesmo fator de satisfação e os escores de descompensação axiológicas de domínio $(\mathrm{r}=-0,50$ para $\mathrm{p}=0,04)$. Como as descompensações médias em tais pólos axiológicos (hierarquia e domínio) foram negativas e indicam que na prática se valoriza mais estes pólos do que se deseja, entende-se que tais avaliações da vida organizacional diminuem a satisfação com os colegas.

\section{DISCUSSÃO E CONCLUSÕES}

Retomando os objetivos apresentados na introdução, em relação à descrição do contexto sócioorganizacional do sistema de bibliotecas, é preciso destacar-se que os resultados encontrados revelam uma instituição que na sua dimensão econômica apresenta um papel social relevante e forte, bem definido, dispõe de uma infra-estrutura física compatível com seus objetivos e um acervo insatisfatório, porém em crescimento. Seu principal problema, na dimensão econômica, para concretizar sua missão na prática cotidiana está na escassez de seus recursos humanos e na multiplicidade de vínculos empregatícios mantidos.

Seus usuários, entre outros aspectos, apontam a necessidade de melhoria de atendimento, o que corrobora o entendimento de que as atitudes comprometidas dos funcionários encontram dificuldades em se manifestar no comportamento concreto dos mesmos (dimensão simbólica).

Na dimensão política, destaca-se que o sistema de bibliotecas apresenta um processo decisório no qual há uma dependência externa acentuada sobre vários aspectos em decorrência de seu status de órgão suplementar de uma universidade pública federal. Internamente, as relações de poder estabelecem-se fundadas numa estrutura organizacional tradicional de linha/staff. Não dispõe de um plano de carreira satisfatório para seus funcionários, realidade que abrange toda a categoria de funcionários técnicoadministrativos das universidades federais.

$\mathrm{Na}$ dimensão simbólica, o frágil consenso sobre as definições de como o trabalho deve ser e a hierarquia confusa dos valores organizacionais no plano ideal caracterizam uma cultura organizacional frágil. Cultura frágil não é uma característica necessariamente negativa ou indesejável. A literatura especializada tem demonstrado que cultura forte nem sempre gera bons resultados. Isto ocorre nos momentos de congruência entre a cultura forte de uma organização e o ambiente externo. Entretanto, a longo prazo pode se constituir em uma característica negativa, impedindo a adaptação a novos contextos (Kotter e Heskett, 1995).

Compete avaliar se esta fragilidade cultural revela características de adaptabilidade e flexibilidade, porém não é isto que os resultados sugerem, pois que na hierarquia dos pólos axiológicos, nos planos ideais e reais, Conservação está entre os pólos mais valorizados e não se observa uma priorização da Autonomia. 


\section{ORGANIZAÇÕES - COMPROMETIMENTO NO TRABALHO E SUA SUSTENTAÇÃO NA CULTURA \\ E CONTEXTO ORGANIZACIONAL \\ Livia de Oliveira Borges - Ana Maria de Souza Lima - Elson Cunha Vilela - Suerda da Silva Guedes Morais}

A fragilidade cultural focalizada na dispersão do que se define como ideal para o trabalho e para a organização, pontua principalmente, que se o caminho a seguir está claro para a cúpula da organização, o mesmo não acontece com os demais participantes. Há portanto uma falta de clareza compartilhada do que seja o papel da organização e sua filosofia.

As descompensações axiológicas de igualitarismo, domínio e autonomia por sua vez revelam a existência de demanda do corpo funcional por mais supervisão e acompanhamento deles mesmos e uma percepção da necessidade de uma mais firmeza na relação com o meio externo. Tal carência sinaliza que a comunicação entre dirigentes e funcionários pode estar sendo insuficiente ou se desenvolvendo de tal maneira que não permite o fortalecimento da cultura organizacional.

Estas carências conjugadas com a fragilidade cultural, provavelmente, associam se ou explicam parcialmente a ausência de programa sistemático de divulgação dos serviços do sistema de bibliotecas, que termina se reduzindo a ações isoladas sob responsabilidade exclusiva do gestores e sem implicação da totalidade do quadro de funcionários com este processo de divulgação.

Essas características simbólicas e/ou culturais são sustentadas pela composição do quadro de pessoal no qual predomina os vínculos temporários (Figura 2), tornando insuficiente os mecanismos comuns (e assistemáticos) de socialização para a transmissão e consolidação cultural.

Sobre as relações dos funcionários com a organização (Objetivo 2), destaca-se os problemas motivacionais, decorrentes da baixa instrumentalidade do desempenho para obter Justiça no trabalho, as insatisfações referentes às promoções e ao salário e o descompasso entre o que desejam do trabalho (auto-expressão e realização) e o que observam na prática. Esses fenômenos adicionados à falta de incorporação da definição de interesses da instituição, implícita na cultura frágil, explicam o descompasso entre nível de comprometimento atitudinal (medido pela escala) e o observado no dia a dia. 
Sustentação Contextual dos Aspectos do Comportamento Organizacional

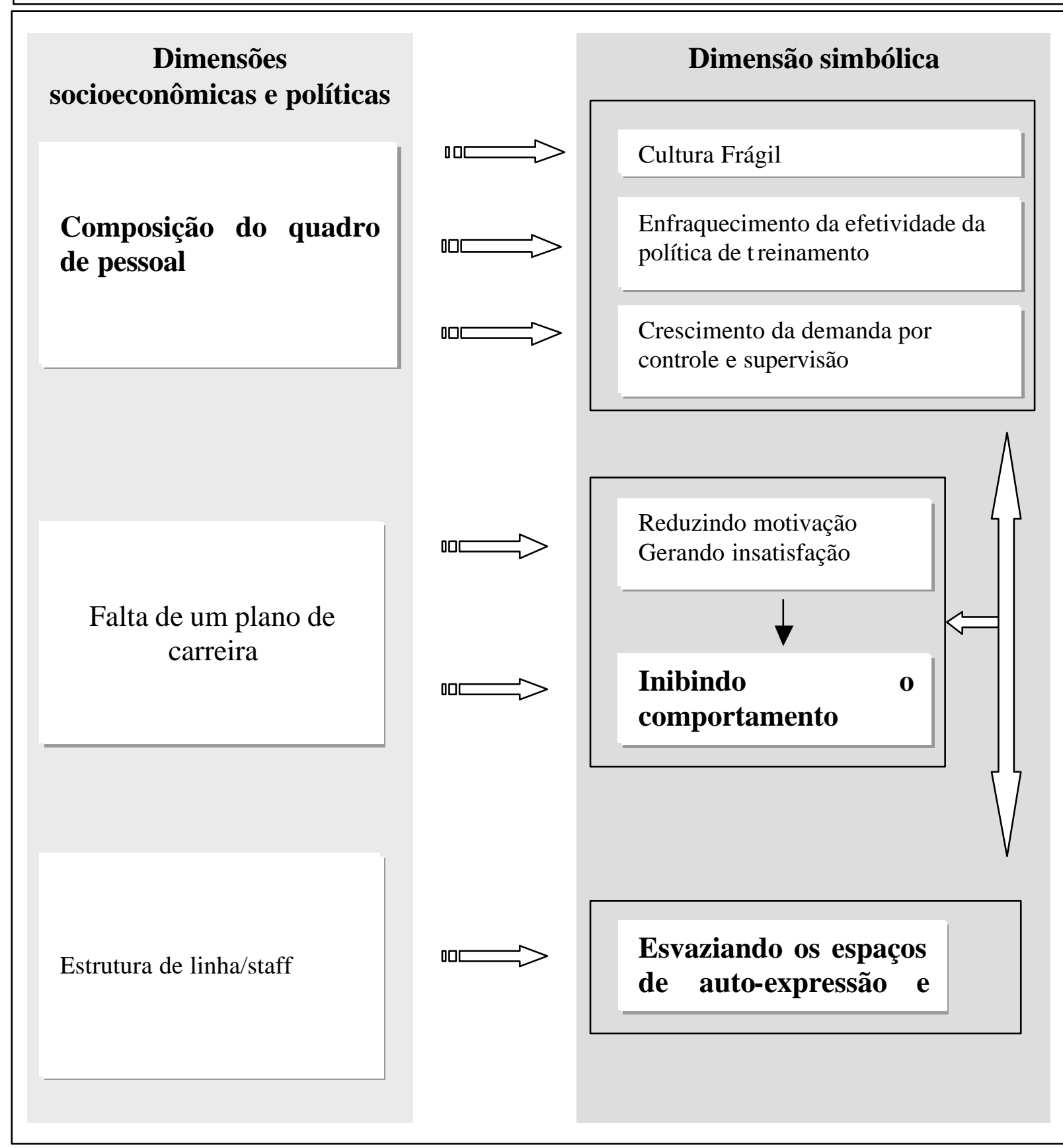

Figura 2. Sustentação Contextual dos Aspectos do Comportamento Organizacional 


\section{ORGANIZAÇÕES - COMPROMETIMENTO NO TRABALHO E SUA SUSTENTAÇÃO NA CULTURA \\ E CONTEXTO ORGANIZACIONAL \\ Livia de Oliveira Borges - Ana Maria de Souza Lima - Elson Cunha Vilela - Suerda da Silva Guedes Morais}

Os descompassos entre as definições do que o trabalho deve ser e o que ele é realmente está sendo sustentado pela falta de espaços de participação como foi assinalado quando se fez referência ao organograma de linha/staff existente na organização. O esvaziamento das iniciativas de criação de espaços de participação citado pela dirigente principal deve ter ocorrido, não pela inexistência de desejo de participar, mas porque fóruns sem engajamento claro no processo de tomada de decisão e não-deliberativo (não-institucionalizados) tendem realmente ao esvaziamento.

O ingresso recente de muitos funcionários, sendo a maior parte com vínculos empregatícios temporários (bolsistas e terceirizados), sem provavelmente haver crescimento da gerência intermediária, oferece sustentação tanto à fragilidade cultural quanto à demanda por controle e supervisão. Embora, observoutse que a política de treinamento da organização é um dos seus pontos fortes, provavelmente tal investimento apresenta resultados inferiores ao desejável devido a rotatividade de parte do quadro funcional (Figura 2).

A multiplicidade de vínculos empregatícios, tornando mais complexa a gestão, a falta de previsão de uma carreira profissional e a concentração do pessoal efetivo em uma área de atividade sustentam os níveis indesejados de satisfação no trabalho, rebaixa os níveis motivacionais, impedindo os funcionários de perceberem o desempenho como instrumental para a consecução dos resultados desejados do trabalho, bem como funcionam como atenuadores das probabilidades das atitudes comprometidas dos trabalhadores de se concretizarem no desempenho (Figura 2).

Desta forma a contratação de pessoal temporário, como alternativa à impossibilidade de contratação de pessoal com contrato por tempo indeterminando (estável), ao mesmo tempo que se constitui numa solução para repor os quantitativos necessários de pessoal, está afetando a gestão cotidiana do trabalho, exigindo dessa maior sofisticação e/ou sistematização.

Os indicadores positivos de centralidade do trabalho, a valorização de Auto-expressão e Realização do trabalho, a existência de alguns funcionários bastante motivados e comprometidos, bem como vários aspectos do contexto organizacional (infra-estrutura material, crescimento do acervo, diversidade de serviços, política de treinamento e abertura dos dirigentes) constituem-se em elos importantes do cenário organizacional para a busca de soluções que conduzam a uma superação dos atuais problemas. Esses indicadores positivos indicam o potencial existente para o estabelecimento de liderança no nível hierárquico intermediário.

Em decorrência dos resultados observados, assinala-se que para tornar realidade o comportamento comprometido com o trabalho e com a organização é necessário solucionar problemas estruturais entre os quais: (1) a contratação de pessoal qualificado para o quadro permanente (2) e um novo plano de carreira. Ambas iniciativas fogem a alçada de decisão daqueles que dirigem o sistema de bibliotecas. Cabe a esses, no entanto, persistir em reivindicar soluções. Ao lado da busca dessas soluções, outras medidas também se fazem necessárias. Essas são medidas internas que para serem implementadas, dependem dos dirigentes e demais funcionários do sistema de bibliotecas:

- Institucionalizar espaços de participação no processo de tomada de decisões, partindo da concepção da sua estrutura organizacional na discussão participativa e na reflexão aprofundada sobre seu organograma, comparando inclusive com a estrutura dos órgãos acadêmicos da universidade que têm contemplado fóruns de decisões colegiadas.

- Repensar a distribuição dos funcionários efetivos por atividades, amenizando a concentração hoje existente, na parte técnica, bem como diferenciando as competências de funcionários efetivos e 


\section{ORGANIZAÇÕES - COMPROMETIMENTO NO TRABALHO E SUA SUSTENTAÇÃO NA CULTURA E CONTEXTO ORGANIZACIONAL \\ Livia de Oliveira Borges - Ana Maria de Souza Lima - Elson Cunha Vilela - Suerda da Silva Guedes Morais}

temporários. Os funcionários efetivos deverão assumir posições de maior responsabilidade e de liderança dos temporários.

- Investir no preparo dos ocupantes de cargos de gerência intermediária, melhorando a supervisão e controle do trabalho e/ou habilitando-os a compatibilizar diferencialmente o exercício da liderança com maturidade profissional do pessoal temporário, principalmente àquele com curto tempo de casa.

- Desenvolver, junto com os níve is intermediários de gestão do sistema de bibliotecas, um trabalho de divulgação e preparação de todo o corpo funcional sobre o papel da organização. Este trabalho deve ganhar um caráter permanente, principalmente, considerando a rotatividade que deve existir entre o pessoal temporário.

- Desenvolver um plano sistemático e integrado de divulgação dos serviços, podendo desenvolver projetos conjuntos com outros órgãos da universidade.

Todas essas recomendações intencionam apoiar o sistema de bibliotecas a conviver com a situação de contar com vários vínculos trabalhistas e com novos padrões de exigência de qualidade. Esses aspectos decorrem de todo o processo de reestruturação produtiva em curso no mundo do trabalho mencionado no início do artigo. Registra-se, adicionalmente, a confiança de que a implementação destas medidas poderá ter um desdobramento saudável na qualidade de vida das pessoas, à medida que a melhoria das relações de cada funcionário com o próprio trabalho e com a instituição tem impacto nas demais esferas de vida.

Chama-se, por fim, atenção que as associações encontradas entre os diferentes construtos aqui explorados, antes de merecerem generalizações, têm sentido no contexto organizacional descrito.

${ }^{1}$ Sugere-se ao leitor interessado em apreender melhor cada um destes elementos consultar outros textos, como: Aktouf (1994); Câmara (1997); Freitas (1999); Gomes (1996); Motta (1995); Motta \& Caldas (1997); Triandis (1994) e Trice e Beyer (1993).

\section{Artigo recebido em 14.03.2003. Aprovado em 18.08.2003.}

\section{REFERÊNCIAS BIBLIOGRÁFICAS}

AKTOUF, O. O simbolismo e a cultura de empresa: dos abusos conceituais às lições empíricas. In: CHANLAT, J. F. (Org.). O indivíduo nas organizações: dimensões esquecidas. São Paulo: Atlas, 1993. v. 2, p. 39-80.

ÁlVARO-ESTRAMiAnA, J. L. Psicología Social: perspectivas teóricas y metodológicas. Madrid: Siglo XXI de España Editores, 1995.

BASTOS, A. V. B. Comprometimento organizacional: um balanço dos resultados e desafios que cercam essa tradição de pesquisa. Revista de Administração de Empresas, v.33, n.3, p.52-64, 1993.

Comprometimento no Trabalho: a estrutura dos vínculos do trabalhador com a organização, a carreira e o sindicato. Tese de Doutorado. Instituo de Psicologia, Universidade de Brasília, Brasília. 1994.

Comprometimento no Trabalho: os caminhos da pesquisa e os seus desafios metodológicos. In: TAMAYO, A.; BORGES-ANDRADE, J. E. e CODO, W. (Orgs.) Trabalho, Organizações $e$ 


\section{ORGANIZAÇÕES - COMPROMETIMENTO NO TRABALHO E SUA SUSTENTAÇÃO NA CULTURA E CONTEXTO ORGANIZACIONAL \\ Livia de Oliveira Borges - Ana Maria de Souza Lima - Elson Cunha Vilela - Suerda da Silva Guedes Morais}

Cultura. São Paulo: Cooperativa de Autores Associados, 1996. p. 105-128.

BORGES-ANDRADE, J.; MARTINS, M. C. F. e ABBAD-OC, G. Estrutura Empírica do Significado do Trabalho: o Caso Brasiliense. In: Sociedade Brasileira de Psicologia (Org.) Resumos de comunicações científicas. XXV Reunião Anual de Psicologia. Ribeirão Preto: SBP, 1995. p.199.

BORGES-ANDRADE, J. E.; CAMESCHI, C. E. e XAVIER, O. S. Comprometimento organizacional em instituição de pesquisa: diferença entre meio e fim. Revista de Administração, v.25, n.4, p.29-43, 1990.

BORGES, L. O. Os Atributos e a Medida do Significado do Trabalho. Psicologia: Teoria e Pesquisa. v.13 n. 2, p. 211-220, 1997)

BORGES, L. O. O Significado do Trabalho e a Socialização Organizacional: um estudo empírico entre trabalhadores da construção habitacional e de redes de supermercados. Tese de doutorado, Instituto de Psicologia, Universidade de Brasília, Brasília. 1998.

BORGES, L. O. Tendências em avaliação Psicológicas na Organizações. In: conselho Regional de Psicologia (Org.), A diversidade da avaliação psicológica: considerações Teóricas e Práticas. João Pessoa: Idéia, 2001. p.123-140.

BORGES, L. O. e ALVES-FILHO, A. A mensuração da motivação e do significado do trabalho. Estudos de Psicologia, v.6, n.2, p.177-194, 2001.

BORGES, L. O. e TAMAYO, Á. A estrutura cognitiva do significado do trabalho. Revista Psicologia: Organizações e Trabalho, v.1, n2, p.11- 44, 2001.

BRIEF, A. P. e NORD, W. R. (Org.) Meaning of occupational work: a collections of essays. Massachusetts/Toronto: Lexington Books, 1990.

ENGLAND, G. W. e MISUMI, J. Work Centrality in Japan and the United States. Journal of CrossCultural Psychology, v.17, n.4, p.399-416, 1986.

GARAY, A. B. S. Reestruturação produtiva e desafios da qualificação: algumas considerações críticas. Anteriores, edição 5, n. 1, v. 3, jun. 1997. Disponível em:

http://read.adm.ufrgs.br/read05/artigo/garay.html. Acesso em: 26 abr. 2002.

GILES, T. R. História do Existencialismo e da Fenomenologia. São Paulo: EPU, 1989.

HOFSTEDE, G. Culture's Consequences: International Differences in Work-Related Values. Newbury Park, London and new Delhi: Sage Publications, 1984.

JAFFE, D. T. The Healthy Company: Research Paradigms for Personal and Organizational Health. Em S. L. SAUTER \& L. R. MURPHY (Org.). Organizational risk factors for job stress. Washington: American Psychological Association, 1995.

KATZELL, R. Contemporary Meta-Trends in Industrial and Organizational Psychology. In: TRIANDIS, H. C.; DUNNETTE, M. D. e HOUGH, L. M. (Orgs.). Handbook of Industrial \& Organizacional Psychology. California: Palo Alto, 1994. v. 4, p. 1-94, 


\section{ORGANIZAÇÕES - COMPROMETIMENTO NO TRABALHO E SUA SUSTENTAÇÃO NA CULTURA E CONTEXTO ORGANIZACIONAL \\ Livia de Oliveira Borges - Ana Maria de Souza Lima - Elson Cunha Vilela - Suerda da Silva Guedes Morais}

KOZLOWSKI, S. W. e KLEIN, K. J. A multilevel approach to theory and research in organizations: contextual, temporal and emergent processes. In: KOZLOWSKI, S. W. e KLEIN, K. J. (Orgs.), Frontiers of Industrial and Organizational Psychology. San Francisco: Jossey-Bass, 2000. p. 3-89.

KIERNAN, M. J. 11 Mandamentos da administração do séc. XXI: o que as empresas de ponta estão fazendo para sobreviver e prosperar no turbulento mundo dos negócios da atualidade. São Paulo: Makron Books, 1998.

KOTTER, J. P. e HESKETT, J. L. Cultura de empresa y rentabilidad. Madrid: Ediciones Díaz de Santos, 1995.

MASLASCH, C. e LEITER, M. P. Trabalho: fonte de prazer ou desgaste? Guia para vencer o estresse na empresa. Campinas: Papirus, 1999.

MATOSO, J. E. L. A desordem no trabalho. São Paulo: Página Aberta, 1995.

MOW International Research Team. The Meaning of Working. London: Academic Press, 1987.

MEDEIROS, C. A. F. Comprometimento organizacional, características pessoais e performance no trabalho: um estudo dos padrões de comprometimento organizacional. Dissertação de Mestrado. Universidade Federal do Rio Grande do Norte, Natal, 1997.

MUCHINSKY, P. M. Psicología Aplicada al Trabajo. Bilbao: Ed. Desclée de Bouwer,1994.

PEIRÓ, J. Ma . Psicología Social de las Organizaciones. In: ALVARO, J. L.,GARRIDO, A. y TORREGROSA, J.R. (Orgs.), Psicología Social Aplicada. Madrid: McGraw-Hill/Interamericana de España, 1996, p.155-183.

ROKEACH, M e BALL-ROKEACH, S. J. Stability and Change in American Value Priorities, 19681981. American Psychologist. v. 44, p. 775-784.1989.

ROS, M. e SCHWARTZ, S.H. Jerarquía de valores en países de la Europa Occidental: una comparación transcultural. Revista Española de Investigaciones Sociológicas, v.69, p.69-87, 1995.

ROBAYO-TAMAYO, M. Relação entre a Síndrome de Burnout e os Valores Organizacionais no Pessoal de enfermagem de dois hospitais públicos. Dissertação de Mestrado. Brasília: Universidade de Brasília. 1997.

ROUSSEAU, S. P. Organizational behavior in the new organizational era. Annual Review Of Psychology, v. 48, p. 515-46, 1997.

SARTRE, J. P. O existencialismo é um humanismo. Lisboa: Editorial Presença, 1961.

SCHEIN, E. H. Organizational Culture. American Psychologist, v. 45, n. 2, p.109-119, 1990.

SCHWARTZ, S. H. A Theory of Cultural Values and Some Implications for Work. Applied Psychology: An International Review, v.8, n.1, p.23-47, 1999.

SCHWARTZ, S. H. e BILSKY, W.. Toward A Universal Psychological Structure of Human Values. Journal of Personality and Social Psychology, v.53, n. 3, p. 550-562, 1987. 


\section{ORGANIZAÇÕES - COMPROMETIMENTO NO TRABALHO E SUA SUSTENTAÇÃO NA CULTURA E CONTEXTO ORGANIZACIONAL \\ Livia de Oliveira Borges - Ana Maria de Souza Lima - Elson Cunha Vilela - Suerda da Silva Guedes Morais}

SCHWARTZ, S. e ROS, M. Values in the West. A Theoretical and Empirical Challenge to the Individualism-Collectivism Cultural Dimension. World Psychology. v. I, n. 2, p. 91-122, 1995.

SOARES, C. R. V. Significado do trabalho: um estudo comparativo de categorias ocupacionais. Dissertação de Mestrado. Universidade de Brasília. Brasília, 1992.

SIQUEIRA, M. Medidas do Comportamento Organizacional. Estudos de Psicologia. v. 7, n. especial, p. $11-18,2002$.

SIQUEIRA, M. M. M. antecedentes de comportamento de cidadania organizacional: análise de um modelo pós-cognitivo. Tese de doutorado defendida no Instituto de Psicologia, Universidade de Brasília. Brasília,1996

SPINK, P. K. O Lugar do lugar na análise Organizacional. Revista de Administração Contemporânea, v.5, (Especial), p.11-34, 2001.

SROUR, R. H. O lugar das organizaões. In SROUR, R. H. (Org.), Poder, cultura e ética nas organizações, Rio de Janeiro: Campus, 1998. p.107-129.

TRACTENBERG, L. A complexidade nas organizações: futuros desafios para o psicólogo frente à reestruturação competitiva. Psicologia: ciência e profissão, Brasília, DF, ano 19, n. 1, p. 14-29, 1999.

TAMAYO, Á. Hierarquia de valores transculturais e brasileiros. Psicologia: Teoria e Pesquisa, v.10, n.2, p.269-285, 1994.

. Valores e clima organizacional. En M. G. T. PAZ y A. TAMAYO (Orgs.). Escola, Saúde e Trabalho. Brasília: Editora Universidade de Brasília, 1999.

. Valores Organizacionais. In: TAMAYO, A.; BORGES -ANDRADE, J. e CODO, W. (Orgs.) Trabalho, Organizações e Cultura. São Paulo: Cooperativa de Autores Associados, p. 157-172, 1996.

TAMAYO, A.; MENDES, A. M. B. e Paz, M. G.T. Inventário de Valores Organizacionais. Estudos de Psicologia, v.5, n.2, p.289-315, 2000.

TRIANDIS, H. C. Cross-Cultural Industrial and Organizational Psychology. Handbook of Industrial \& Organizational Psychology. California: Consulting Psychology Press. 1994a. v. 4, 103-162.

TRIANDIS, H. C. Culture and Social Behavior. New York: McGraw-Hill, 1994b.

VROOM, V. H. Work and Motivation. New York: Wiley. 1995. (Obra originalmente publicada em 1964)

WEICK, K. E. \& QUINN, R. E. (1999). Organizational Change And Development. Annual Review Of Psychology, 50, 361-386.

WILPERT, B. (1995). Organizational Behavior. Annual Review Of Psychology, v. 46, p. 59-90. 


\section{ORGANIZAÇÕES - COMPROMETIMENTO NO TRABALHO E SUA SUSTENTAÇÃO NA CULTURA E CONTEXTO ORGANIZACIONAL \\ Livia de Oliveira Borges - Ana Maria de Souza Lima - Elson Cunha Vilela - Suerda da Silva Guedes Morais}

\section{Livia de Oliveira Borges}

Doutora de Psicologia Organizacional e do Trabalho pelo Instituto de Psicologia da Universidade de Brasília, com estágio na Universidade Complutense de Madri.

E-mail: liviab@digi.com.br

Endereço: Rua Prof. Luis Carlos Teixeira, no 10 - Bairro Lagoa Nova, Natal - RN, 59075-130.

Interesses de Pesquisa: significado do trabalho, cultura organizacional, saúde no trabalho, comportamento organizacional, socialização organizacional.

\section{Ana Maria de Souza Lima}

Mestre em Psicologia pela Universidade Federal do Rio Grande do Norte.

E-mail: anamariasl@banconordeste.gov.br

Endereço: Rua Francisco Pignataro, 1910 - Capim Macio - Natal - RN, 59082-070.

Interesses de Pesquisa: comportamento organizacional, comprometimento no trabalho, orientação profissional, significado do trabalho, cultura organizacional.

\section{Elson Cunha Vilela}

Mestre em Psicologia pela Universidade Federal do Rio Grande do Norte.

E-mail: elsonvilela@uol.com.br

Endereço: Av. Amintas Barros, 4972. Nova Descoberta. Natal - RN, 59075-250.

Interesses de Pesquisa: comportamento organizacional, escolha acadêmica, orientação profissional, significado do trabalho, cultura organizacional.

\section{Suerda da Silva Guedes Morais}

Psicóloga pela Universidade Federal do Rio Grande do Norte.

E-mail: suerdapsi@ig.com.br

Endereço: R. Ismael Pereira da silva, 1756. Bloco F, apto. 104. Capim Macio. Natal - RN, 59082-000.

Interesses de Pesquisa: significado do trabalho, cultura organizacional, saúde no trabalho, comportamento organizacional, socialização organizacional. 